\title{
A Rational Approach to Improving Productivity in Recombinant Pichia pastoris Fermentation
}

\author{
Marc C. d'Anjou, Andrew J. Daugulis \\ Department of Chemical Engineering, Queen's University, Kingston, \\ Ontario K7L 3N6, Canada; telephone: 613-533-2784; fax: 613-533-6637; \\ e-mail: daugulis@chee.queensu.ca
}

Received 13 February 2000; accepted 22 June 2000

\begin{abstract}
A Mut ${ }^{\mathrm{S}}$ Pichia pastoris strain that had been genetically modified to produce and secrete sea raven antifreeze protein was used as a model system to demonstrate the implementation of a rational, model-based approach to improve process productivity. A set of glycerol/methanol mixed-feed continuous stirred-tank reactor (CSTR) experiments was performed at the 5-L scale to characterize the relationship between the specific growth rate and the cell yield on methanol, the specific methanol consumption rate, the specific recombinant protein formation rate, and the productivity based on secreted protein levels. The range of dilution rates studied was 0.01 to $0.10 \mathrm{~h}^{-1}$, and the residual methanol concentration was kept constant at approximately $2 \mathrm{~g} / \mathrm{L}$ (below the inhibitory (evel). With the assumption that the cell yield on glycerol was constant, the cell yield on methanol increased from approximately 0.5 to 1.5 over the range studied. A maximum specific methanol consumption rate of $20 \mathrm{mg} / \mathrm{g} \cdot \mathrm{h}$ was achieved at a dilution rate of 0.06 $\mathrm{h}^{-1}$. The specific product formation rate and the volumetric productivity based on product continued to increase over the range of dilution rates studied, and the maximum values were $0.06 \mathrm{mg} / \mathrm{g} \cdot \mathrm{h}$ and $1.7 \mathrm{mg} / \mathrm{L} \cdot \mathrm{h}$, respectively. Therefore, no evidence of repression by glycerol was observed over this range, and operating at the highest dilution rate studied maximized productivity. Fedbatch mass balance equations, based on Monod-type kinetics and parameters derived from data collected during the CSTR work, were then used to predict cell growth and recombinant protein production and to develop an exponential feeding strategy using two carbon sources. Two exponential fed-batch fermentations were conducted according to the predicted feeding strategy at specific growth rates of $0.03 \mathrm{~h}^{-1}$ and $0.07 \mathrm{~h}^{-1}$ to verify the accuracy of the model. Cell growth was accurately predicted in both fed-batch runs; however, the model underestimated recombinant product concentration. The overall volumetric productivity of both runs was approximately $2.2 \mathrm{mg} / \mathrm{L} \cdot \mathrm{h}$, representing a tenfold increase in the productivity compared with a heuristic feeding strategy. (c) 2001 John Wiley \& Sons, Inc. Biotechnol Bioeng 72: 1-11, 2001.
\end{abstract}

Keywords: Pichia pastoris; recombinant proteins; fedbatch; fermentation

Correspondence to: A. Daugulis

Contract grant sponsors: Lloyd Carr-Harris Foundation; Natural Sciences and Engineering Research Council of Canada

\section{INTRODUCTION}

Pichia pastoris, an ascosporogenic, methylotrophic yeast, is finding increasing use as a host for the expression of a wide variety of recombinant proteins at the bench and pilot scales. There are a number of excellent reviews describing the general features of this yeast expression system (Cregg and Higgins, 1995; Faber et al., 1995; Romanos et al., 1992; Vedvick, 1991) and examining recent advances in its development and application (Cregg et al., 1993; Hollenberg and Gellissen, 1997; Romanos, 1995; Sreekrishna et al., 1997). At first glance, Pichia seems to be an ideal host, because: (i) it is a simple microbe that is capable of growth to high cell densities on inexpensive, defined media using well-developed fermentation protocols; (ii) expression of foreign proteins in Pichia is driven by the very strong and tightly regulated $A O X 1$ promoter that has been exploited by a number of vectors with reasonable transformation efficiencies showing stable chromosomal integration; (iii) as simple eukaryotes, yeasts are capable of many of the same posttranslational modifications to proteins as higher animals; and (iv) yeasts are capable of secreting high levels of many proteins, simplifying downstream purification. However, simply inserting a gene of interest into a vector and transforming a microbial host is no guarantee of a viable bioprocess. Expression levels reported in the literature for foreign proteins produced in Pichia are highly variable and range from the milligrams-per-liter to grams-per-liter levels.

The expression level for a given recombinant protein produced in Pichia seems to be decided largely by its inherent properties such as the amino acid sequence, the tertiary structure, and the site of expression (Sreekrishna et al., 1997). There are a number of approaches that can be taken to improve this critical parameter; however, many of these are empirical by nature, and their reporting is anecdotal. Another strategy, which has been applied successfully in more developed recombinant expression systems, such as Escherichia coli and Saccharomyces cerevisiae (Baheri et al., 1997; Hardjito et al., 1992), involves taking a systematic, rational approach to optimizing the entire process. This strategy involves initiating a study designed to identify and to characterize trends in the behavior of the system. These 
observations are then formalized as a simple, accurate model and used to initiate an optimization study of the system to maximize process productivity. In addition to addressing the process as a whole, rather than narrowly focusing on the maximum expression level, this methodology is superior because it simplifies process scale-up, can be used for process troubleshooting, and can be applied to a range of recombinant products produced in the same host. The conclusions developed examining a model recombinant protein-host system can be made relevant to another product with a minimum of experimental work.

Work performed by Loewen et al. (1997) developed the Pichia pastoris expression system into an efficient process for producing recombinant sea raven antifreeze protein in quantities sufficient for testing its biotechnology properties. This was accomplished by evaluating a number of empirical approaches to boosting expression levels. The most successful of these, fed-batch fermentation of a Mut ${ }^{\mathrm{S}}$ strain using a mixed glycerol/methanol feeding strategy, produced 30 $\mathrm{mg} / \mathrm{L}$ of recombinant srAFP after $156 \mathrm{~h}$ of total fermentation time. This represents a net volumetric productivity of $0.20 \mathrm{mg} / \mathrm{L} \cdot \mathrm{h}$. This result was chosen as a benchmark for this study for two reasons:

1. Loewen and coworkers concluded that this represents an efficient system for the production of recombinant sea raven AFP in quantities sufficient for testing biotechnological applications. However, this system's productivity is likely not sufficiently high to encourage commercial production of a low- to middle-value product such as AFP.

2. Several empirical approaches were used to improve on this base case, but were not successful. These included use of a $\mathrm{Mut}^{+}$phenotype strain and supplementing the medium with peptone to reduce the incidence of proteolysis. These results indicate that a rational, model-based approach might be a useful tool for improving the poor expression level of this recombinant system.

This article describes the implementation of an experimental and modeling study of this system designed to demonstrate the value of a rational, systematic approach to increasing the production of recombinant proteins in Pichia pastoris.

\section{MATERIALS AND METHODS}

\section{Microorganism, Vector Construction, and Transformation}

A GS115 (his4) strain of the methylotrophic yeast Pichia pastoris was supplied by Invitrogen Corp. (San Diego, CA). GS115 is an auxotrophic mutant deficient in histidine dehydrogenase requiring histidine supplementation.

Sea raven AFP cDNA gene was cloned into the pPIC9 $P$. pastoris $-E$. coli shuttle vector according to Loewen et al. (1997) and Loewen (1997). This vector contains the Pichia pastoris HIS4 gene for selection using a his4 mutant, such as GS115, and the ampicillin-resistance gene for selection in E. coli. Mature sea raven cDNA was modified by PCR primer design such that tandem EcoRI restriction enzyme sites were introduced upstream of the N-terminus of the mature srAFP, and a NotI site was introduced downstream of the stop codon. Also, a fragment encoding a C-terminal 6-His tag was inserted immediately upstream of the stop codon. The final plasmid was described as $\mathrm{pPIC} 9-\mathrm{SR}_{\mathrm{m}}{ }^{-}$ CTHT.

Ten milligrams of $\mathrm{pPIC} 9-\mathrm{SR}_{\mathrm{m}}$-CTHT vector DNA produced in $E$. coli was linearized by restriction enzyme digestion with BglII and introduced into Pichia pastoris GS115 by the sphaeroplast transformation procedure as described by Cregg et al. (1985). The vector linearized in this way integrates into the Pichia genome by double-crossover integration (i.e., gene replacement) at the $A O X 1$ locus. The resulting phenotype was $\mathrm{Mut}^{\mathrm{S}} \mathrm{His}^{+}$. The putative Pichia pastoris clones were plated on MD plates for selection of His $^{+}$transformants.

\section{Culture Media}

The following media were used:

- Minimal dextrose medium (MD): dextrose, $20 \mathrm{~g} / \mathrm{L}$; yeast nitrogen base without amino acids, $13.4 \mathrm{~g} / \mathrm{L}$; biotin, 400 $\mathrm{mg} / \mathrm{L} ; 15 \mathrm{~g} / \mathrm{L}$ agar.

- Buffered glycerol-complex medium (BMGY): yeast extract, $10 \mathrm{~g} / \mathrm{L}$; meat peptone, $20 \mathrm{~g} / \mathrm{L} ; 100 \mathrm{~m} M$ potassium phosphate buffer ( $\mathrm{pH} 6.0$ ); yeast nitrogen base without amino acids, $13.4 \mathrm{~g} / \mathrm{L}$; biotin, $400 \mathrm{mg} / \mathrm{L}$; glycerol, 10 $\mathrm{mL} / \mathrm{L}$.

- Buffered methanol-complex medium (BMMY): yeast extract, $10 \mathrm{~g} / \mathrm{L}$; meat peptone, $20 \mathrm{~g} / \mathrm{L} ; 100 \mathrm{~m} M$ potassium phosphate buffer ( $\mathrm{pH} 6.0$ ); yeast nitrogen base without amino acids, $13.4 \mathrm{~g} / \mathrm{L}$; biotin, $400 \mathrm{mg} / \mathrm{L}$; methanol, 5 $\mathrm{mL} / \mathrm{L}$.

- Minimal glycerol medium (MGY): yeast nitrogen base without amino acids, $13.4 \mathrm{~g} / \mathrm{L}$; biotin, $400 \mathrm{mg} / \mathrm{L}$; glycerol, $10 \mathrm{~mL} / \mathrm{L}$.

- Fermentation medium: glycerol, $50 \mathrm{~g} / \mathrm{L} ;\left(\mathrm{NH}_{4}\right)_{2} \mathrm{SO}_{4}, 20$ $\mathrm{g} / \mathrm{L} ; \mathrm{KH}_{2} \mathrm{PO}_{4}, 12 \mathrm{~g} / \mathrm{L} ; \mathrm{MgSO}_{4} \cdot 7 \mathrm{H}_{2} \mathrm{O}, 4.7 \mathrm{~g} / \mathrm{L}$; $\mathrm{CaCl}_{2} \cdot 2 \mathrm{H}_{2} \mathrm{O}, 0.36 \mathrm{~g} / \mathrm{L} ; \mathrm{pH}$ adjusted to 5.5 with $5 \mathrm{M}$ $\mathrm{KOH}$.

- Trace elements solution: $\mathrm{CaSO}_{4} \cdot 5 \mathrm{H}_{2} \mathrm{O}, 0.2 \mathrm{mM}$; KI, $1.25 \mathrm{~m} M ; \mathrm{MnSO}_{4} \cdot 4 \mathrm{H}_{2} \mathrm{O}, 4.5 \mathrm{~m} M ; \mathrm{Na}_{2} \mathrm{MoO}_{4} \cdot 2 \mathrm{H}_{2} \mathrm{O}, 2$ $\mathrm{m} M ; \mathrm{H}_{3} \mathrm{BO}_{3}, 0.75 \mathrm{~m} M ; \mathrm{ZnSO}_{4} \cdot 7 \mathrm{H}_{2} \mathrm{O}, 17.5 \mathrm{~m}$, $\mathrm{FeCl}_{3} \cdot 6 \mathrm{H}_{2} \mathrm{O}, 44.5 \mathrm{mM}$; biotin, $400 \mathrm{mg} / \mathrm{L}$.

\section{Experimental Procedure}

A single colony from an MD plate was used to inoculate 10 $\mathrm{mL}$ of BMGY in a sterile $50-\mathrm{mL}$ conical centrifuge tube. The culture was grown for $24 \mathrm{~h}$ at $30^{\circ} \mathrm{C}$ and $250 \mathrm{rpm}$ in a gyratory water-bath shaker. Then, $2 \times 1 \mathrm{~mL}$ of this culture was transferred aseptically to $2 \times 300 \mathrm{~mL}$ of sterile MGY 
medium in $2 \times 1$-L Erlenmeyer flasks. These cultures were grown for $48 \mathrm{~h}$ at $30^{\circ} \mathrm{C}$ and $250 \mathrm{rpm}$ and transferred aseptically to an autoclaved 2-L inoculum jar used to aseptically inoculate the fermentor. Fermentation was carried out in two Chemap FZ-3000 stirred vessel bioreactors with a 14-L (nominal volume) SG-type fermentor vessel. Dissolved oxygen was monitored by an Ingold sterilizable polarographic dissolved oxygen electrode. $\mathrm{pH}$ was monitored by an Ingold InFit 764-50 sterilizable probe. Fermentation was carried out at $30^{\circ} \mathrm{C}$. Aeration was set at $15 \mathrm{~L} / \mathrm{min}$ (2 to 3 vvm) and the pressure was maintained slightly above $(<0.5$ psi) ambient pressure, by means of a pressure regulator on the air exhaust group, to minimize opportunities for contamination. Agitation was set between 750 and $900 \mathrm{rpm}$ to maintain dissolved oxygen levels at $>30 \%$ of saturation. If the oxygen uptake rate exceeded the ability of increased agitation to meet it, pure oxygen was added as required. The $\mathrm{pH}$ was maintained at 5.5 by the addition of $5 \mathrm{M} \mathrm{KOH}$. Antifoam 204 (1.5 mL; Sigma Chemical Co., St. Louis, MO) was added prior to inoculation, and as needed thereafter, to prevent excessive foaming. Twenty-five-milliliter samples were taken as required for cell density estimates, substrate analysis, and protein analysis. Samples were centrifuged at $9000 \mathrm{rpm}$ for $5 \mathrm{~min}$. The pellet was discarded and $15 \mathrm{~mL}$ of the supernatant was retained for further analysis. Samples were stored at $+4^{\circ} \mathrm{C}$ or $-20^{\circ} \mathrm{C}$.

\section{Continuous Culture}

Cultures were grown in batch phase until the exhaustion of the initial glycerol charge was indicated by a sudden increase in the dissolved oxygen level and substrate analysis showed zero glycerol. At this point, a length of sterile stainless-steel tubing $(\sim 20 \mathrm{~cm})$ welded to an injection needle was inserted aseptically into the fermentation vessel through an inlet port on the cover. A length of sterile tubing ran from the outlet needle, through a peristaltic pump with speed controller, and into a $20-\mathrm{L}$ glass carboy. The length of the stainless-steel tubing was such that the fermentation broth was siphoned off to maintain a constant liquid volume of 5 L. The substrate feed solution consisted of the fermentation medium with sufficient methanol added to ensure a steadystate residual methanol concentration of 1 to $2 \mathrm{~g} / \mathrm{L}$, and 0.75 $\mathrm{mL} / \mathrm{L}$ Antifoam 204 was added to control foaming. The substrate feed solution was prepared without methanol in $15-\mathrm{L}$ batches in a $20-\mathrm{L}$ glass carboy and autoclaved. Methanol was added aseptically once it had cooled to ambient temperature. Substrate feed was pumped into the fermentor by a Gemini PC-1 pump (Alaris Medical, San Diego, CA) and introduced below the surface of the fermentation broth by means of a short length $(\sim 15 \mathrm{~cm})$ of PharMed tubing attached to the injection needle. This was done to ensure proper mixing of the feed in the CSTR culture. Samples were withdrawn periodically (the frequency was determined by the dilution rate) for testing substrate levels and measuring cell density. The culture was maintained at constant dilution rate and feed methanol concentration until steady state was achieved (as determined by a relatively stable dissolved oxygen reading). Protein analysis and quantification was carried out only on steady-state samples.

\section{Fed-Batch Operation}

Cultures were grown to glycerol exhaustion as above. A bolus of 15 to $20 \mathrm{~mL}$ of methanol was injected aseptically into the culture to set the methanol concentration at $0.2 \%$ (w/v). A 100\% methanol feed was started using a Gemini PC-1 pump. This feed was continued for $12 \mathrm{~h}$ or $24 \mathrm{~h}$ to ensure full induction of the methanol metabolic pathway and the $A O X 1$ promoter driving heterologous protein production. Samples were withdrawn periodically and analyzed for methanol levels, and the feed rate was adjusted accordingly to maintain 1 to $2 \mathrm{~g} / \mathrm{L}$ of residual methanol. Following this induction period, a mixed glycerol/methanol feed was started. This feed solution contained $50 \%$ (v/v) glycerol, the fermentation trace mineral solution, and sufficient methanol to ensure a concentration between 1 and $2 \mathrm{~g} / \mathrm{L}$. The glycerol/ trace mineral solution was autoclaved and allowed to cool before the methanol was added. The substrate feed rate varied according to the fermentation feeding strategy. Samples were withdrawn periodically to measure residual glycerol and methanol concentrations, cell density, and protein analysis. Fed-batch fermentation was continued until there was no further cell growth observed.

\section{Analyses}

\section{Cell Density}

Cell density was estimated from optical density measurements using a Brinkmann PC800 colorimeter operating at $650 \mathrm{~nm}$. Samples were serially diluted to obtain readings in the linear range (optical density [OD] <0.70) and compared with a calibration curve prepared from known standards.

\section{Substrate Concentration}

Glycerol and methanol levels in the fermentation broth were determined by HPLC. The HPLC system consists of a Waters 520 HPLC pump and a Waters 410 Differential Refractometer (Waters Millipore, Milford, MA). The HPLC column was a Waters Sugar-Pak I. Chromatogram data were collected by the PC-based MAXIMA 820 software package calibrated using known standards. Fermentation broth samples were passed through Waters C18 Sep-Pak cartridges to remove proteins and cellular material prior to injection to minimize column fouling.

\section{Recombinant Protein Quantification}

Sodium dodecylsulfate-polyacrylamide gel electrophoresis $(S D S-P A G E)$. Fermentation broth samples were analyzed 
by denaturing $15 \%$ SDS-PAGE using the tris/tricine buffer system of Schaegger and von Jagow (1987).

Gels were run for approximately $1 \mathrm{~h}$ at $100 \mathrm{~V}$ using the Bio-Rad Mini-Protean II gel casting system. Gels were either stained by Coomassie blue $(0.25 \%)$ and destained using $10 \%$ methanol and $5 \%$ acetic acid to analyze total protein, or western immunoblotted.

Western immunoblotting. Following SDS-PAGE, gels were electroblotted onto Immobilon P PVDF nylon membranes (Millipore, Bedford, MA) according to the procedure described in Harlow and Lane (1988). Gel transfer was done at $15 \mathrm{~V}$ overnight at $+4^{\circ} \mathrm{C}$. The membranes were blocked in a $5 \%$ skim milk buffer for at least $6 \mathrm{~h}$ at $+4^{\circ} \mathrm{C}$. The membranes were subsequently washed with a Tris/Tween-20 buffer, incubated for $1 \mathrm{~h}$ at ambient temperature with rabbit anti-srAFP antiserum, washed again, and finally incubated for 20 min with a goat anti-rabbit immoglobulin $\mathrm{G}$ (IgG) antibody-horseradish peroxidase conjugate. After a final wash cycle with Tris/Tween-20 buffer, membranes were reacted for 1 min with NEN Renaissance enhanced western blot chemiluminescence reagent, blotted dry, and exposed to Kodak X-Omat blue X-ray film.

Quantification was carried out by visual inspection of band intensity against known standards, or by image analysis of scanned films. Films were scanned by a HewlettPackard DeskScan II as bitmaps, and analyzed by SCION IMAGE version 3b (Scion Corp., Frederick, MD). SCION IMAGE can analyze and interpolate band intensities of unknowns against known standards of the scanned bitmap images.

\section{MODEL DEVELOPMENT}

\section{Fed-Batch System}

The fed-batch system can be described by a set of fed-batch balances on the biomass, substrate concentration, system volume, and recombinant product concentration in the fermentation broth. Because this Pichia strain is grown on a mixed glycerol/methanol feed during the production phase of the fermentation, the contribution of both glycerol and methanol to cell growth must be considered. The following fed-batch mass balances describe this system:

$$
\begin{aligned}
\frac{d(X V)}{d t} & =\mu X V-F X \\
\frac{d(G V)}{d t} & =F\left(G_{o}-G\right)-q_{G} X V \\
\frac{d(M V)}{d t} & =F\left(M_{o}-M\right)-q_{M} X V \\
\frac{d(P V)}{d t} & =q_{P} X V-F P \\
\frac{d V}{d t} & =F
\end{aligned}
$$

where $X$ is the cell density $\left(\mathrm{g}_{\mathrm{CDW}} / \mathrm{L}\right), V$ is the volume $(\mathrm{L})$, $F$ is the substrate feed rate $(\mathrm{L} / \mathrm{h}), G$ is the glycerol concentration $(\mathrm{g} / \mathrm{L}) ; G_{o}$ is the feed glycerol concentration $(\mathrm{g} / \mathrm{L}), q_{G}$ is the specific glycerol consumption rate $\left(\mathrm{g}_{G} / \mathrm{g}_{X} \cdot \mathrm{h}\right), M$ is the methanol concentration $(\mathrm{g} / \mathrm{L}), M_{o}$ is the feed methanol concentration $(\mathrm{g} / \mathrm{L}), q_{M}$ is the specific methanol consumption rate $\left(\mathrm{g}_{M} / \mathrm{g}_{X} \cdot \mathrm{h}\right), P$ is the heterologous protein concentration $(\mathrm{g} / \mathrm{L})$, and $q_{P}$ is the specific heterologous protein production rate $\left(\mathrm{g}_{P} / \mathrm{g}_{X} \cdot \mathrm{h}\right)$.

It is possible to represent the cell density as a function of the total mass of substrate added and the cell yields. During mixed substrate growth, the formation of biomass from glycerol and methanol is additive (Egli et al., 1986):

$$
\begin{array}{r}
X\left(t_{o}\right) V\left(t_{o}\right)+Y_{X / G}\left(G_{o} \int_{t_{o}}^{t} F(t) d t-G(t) V(t)\right) \\
+Y_{X / M}\left(M_{o} \int_{t_{o}}^{t} F(t) d t-M(t) V(t)\right)
\end{array}
$$

where $Y_{X / G}$ is the cell yield on glycerol, $Y_{X / M}$ is the cell yield on methanol, and $t_{o}$ is the time at the start of the fed-batch period. To solve this series of differential equations, it is necessary to make some assumptions and simplifications. The methodology of solving this series of equations is as follows:

1. The system is initially considered as a batch system. During this batch growth phase, where the initial glycerol charge is consumed, the system volume balance may be neglected as the volume is not changing. The product balance may be neglected due to repression of heterologous protein production by glycerol. The extent of derepression at the end of the batch phase due to glycerol exhaustion is assumed to be negligible. Also, during the batch growth phase, the specific growth rate of the cells and the cell yield on glycerol are assumed to be constant. Therefore, during batch growth, the system may be represented by:

$$
\begin{aligned}
& X=X_{o} e^{\mu\left(t-t_{\mathrm{lag}}\right)} \\
& G=G_{o}-\frac{1}{Y_{X / G}}\left(X-X_{o}\right)
\end{aligned}
$$

where $\mu$ is the specific growth rate on glycerol $\left(\mathrm{h}^{-1}\right), G_{o}$ is the initial glycerol charge to the fermentor, and $t_{\text {lag }}$ is the time required for the culture to enter the exponential growth phase following inoculation. For $t<t_{\text {lag }}, X=; X_{o}$. The endpoint solution (i.e., time at glycerol exhaustion) of the batch growth model is used to generate initial conditions $\left[X\left(t_{o}\right), V\left(t_{o}\right)\right]$ for the fed-batch period.

2. With the available experimental set-up, it is not possible to differentiate between the contributions of glycerol and methanol to cell growth. Therefore, it is also not possible to solve for the cell yield based on methanol and the cell yield based on glycerol independently. The cell yield on glycerol is assumed to be constant and set at the value determined during the batch growth phase throughout 
the fed-batch phase. While this is not a true representation of the cellular behavior reported in the literature (Egli et al., 1986), the model should accurately predict cell growth on a mixed feed provided that this assumption is consistently applied.

3. To ensure that the methanol metabolic pathway is active and that the $A O X 1$ promoter driving heterologous protein production is induced, a 12-h induction phase where the cells are fed only methanol is initiated immediately after the end of the batch growth phase. Cell growth is considered to be negligible during this induction period.

4. Methanol concentrations are maintained at levels sufficient to fully induce heterologous protein production, yet not so high as to be inhibitory to cell growth or heterologous protein expression. The Invitrogen fermentation process guidelines recommend that methanol levels be maintained below $3 \mathrm{~g} / \mathrm{L}$, but that residual methanol be present such that it is not limiting. Therefore, it is desirable to keep methanol levels between 1 and $2 \mathrm{~g} / \mathrm{L}$. The concentration of methanol in fed-batch and CSTR experiments is controlled according to the method described by d'Anjou and Daugulis (2000). It is assumed that the parameters in the model will not vary significantly over this narrow range of methanol concentration, and can be considered constant with respect to $M$.

5. Due to glycerol's repression of foreign protein production, the average specific growth rate of the fed-batch culture must be kept sufficiently far from $\mu_{\max }$ to ensure that no residual glycerol is allowed to accumulate in the broth. Therefore, $\mu<1 / 2 \mu_{\max }$.

6. Because the residual glycerol concentration is essentially kept at zero, it is possible to assume a quasi-steady state on the glycerol balance. Therefore, the glycerol balance need not be considered during the fed-batch induction and production phases.

7. It is assumed that all parameters are constant with respect to time.

Even with these assumptions and simplifications, it is still necessary to solve for $\mu, q_{M}, Y_{X / M}$, and $q_{P}$ to describe the system behavior during the fed-batch production phase. Following statements 4 and 6 , the last three of these parameters appear only as functions of the specific growth rate, $\mu$. Therefore, experiments were conducted to determine these parameters as $f(\mu)$. It is possible to maintain $\mu$ at a constant value in a fed-batch culture by using an exponential feeding strategy. For a single substrate $(S)$ fed-batch system where a quasi-steady state exists for the residual substrate concentration, the specific growth rate of the culture at time $t$ is given as:

$$
\mu(t)=\frac{Y_{X / S} S_{o} F(t)}{X(t) V(t)}
$$

If the specific growth rate is controlled at a constant rate, $\mu$, and the fed-batch cell balance is integrated [Eq. (10)], it is possible to solve for $F(t)$ in Eq. (11):

$$
\begin{aligned}
X(t) V(t) & =X\left(t_{o}\right) V\left(t_{o}\right) \exp \left(\mu\left(t-t_{o}\right)\right) \\
F(t) & =\frac{\mu X(t) V(t)}{S_{o} Y_{X / S}}=\frac{\mu X\left(t_{o}\right) V\left(t_{o}\right) \exp \left(\mu\left(t-t_{o}\right)\right)}{S_{o} Y_{X / S}}
\end{aligned}
$$

Therefore, provided that accurate measures of the cell density and culture volume at the start of the fed-batch period are available, it is possible to design a substrate feeding strategy to maintain a constant specific growth rate in fedbatch fermentation.

If we assume that this feeding profile can be extended to two substrates, provided that the yield coefficients are constant at the fixed growth rate, it is necessary to develop a compound cell yield (based on an average weighted by the relative concentrations of the methanol and glycerol in the feed) and substrate feed concentration terms such that the equation for $F(t)$ becomes:

$$
\begin{aligned}
F(t) & =\frac{\mu V\left(t_{o}\right) X\left(t_{o}\right)}{S_{o} Y_{X / S}} \exp \left[\left(\mu\left(t-t_{o}\right)\right)\right] \\
S_{o} & =\left(G_{o}+M_{o}\right) \\
Y_{X / S} & =\left(Y_{X / G} \frac{G_{o}}{G_{o}+M_{o}}+Y_{X / M} \frac{M_{o}}{G_{o}+M_{o}}\right)
\end{aligned}
$$

Returning to Eqs. (1)-(5) (the fed-batch mass balances), it is now possible to solve for $V, X, M$, and $P$ as functions of time from the start of the fed-batch production phase:

$$
\begin{aligned}
\int_{t_{o}}^{t} F(t) d t= & \frac{V\left(t_{o}\right) X\left(t_{o}\right)}{S_{o} Y_{X / S}} \exp \left[\left(\mu\left(t-t_{o}\right)\right)\right] \\
V(t)= & V\left(t_{o}\right)+\int_{t_{o}}^{t} F(t) d t \\
X(t)= & \frac{X\left(t_{o}\right) V\left(t_{o}\right)+Y_{X / G}\left(G_{o / M} \int_{t_{o}}^{t} F(t) d t\right)}{\left.M_{o} \int_{t_{o}}^{t} F(t) d t-M(t) V(t)\right)} \\
M(t)= & \frac{M_{o}\left(\int_{t_{o}}^{t} F(t) d t\right)-q_{M} \int_{t_{o}}^{t} X(t) V(t) d t}{V(t)} \\
P(t)= & \frac{q_{P} \int_{t_{o}}^{t} X(t) V(t) d t}{V(t)} \cong 0 \\
G(t) \cong & 0
\end{aligned}
$$

Because $M(t)$ and $X(t)$ both appear in Eqs. (17) and (18), and the product balance requires the solution for $X(t)$, it is necessary to solve this system of equations numerically according to Eqs. (21)-(23): 


$$
\begin{gathered}
M_{n}=\frac{M_{o}\left(\int_{t_{n-t}}^{t_{n}} F(t) d t\right)+M_{n-1} V_{n-1}-q_{M} X_{n-1} V_{n-1} \Delta t}{V_{n}} \\
X\left(t_{o}\right) V\left(t_{o}\right)+Y_{X / G}\left(G_{o} \int_{t_{o}}^{t} F(t) d t\right) \\
X(t)=\frac{+Y_{X / M}\left(M_{o} \int_{t_{o}}^{t} F(t) d t-M_{n} V(t)\right)}{V(t)} \\
P_{n}=\frac{q_{P} \frac{1}{2}\left(X_{n-1} V_{n-1}+X_{n} V_{n}\right) \Delta t}{V_{n}}
\end{gathered}
$$

$P_{n}$ is protein produced in the interval $\Delta t$. The use of the cell density from the previous time step should not introduce a significant error, provided that the time step is sufficiently small compared with the change in the cell density (i.e., $\Delta t$ $<1 / \mu$ ). This is a simple model in which all of the variables can be solved for explicitly. Time profiles for each of the relevant outputs can be determined with the model and compared with fed-batch experimental data to evaluate the accuracy of the model.

\section{CSTR System}

As this is a steady-state system, the volume $(V)$ is constant. The concentration of the two substrates (glycerol, $G$, and methanol, $M$ ) in the vessel are affected by the inlet feed rate, the inlet feed concentration $\left(G_{o}\right.$ and $\left.M_{o}\right)$, and the rate of consumption of the substrates, which is largely determined by the cell concentration, $X$. The cell concentration is related to the inlet substrate feed concentrations by the cellular yield coefficients. The product concentration, $P$, is a function of the specific product formation rate and the cell density. The vessel is assumed to be well mixed, such that no spatial variation in any of the parameters exists. Assuming that the concentration of glycerol is negligible, CSTR mass balances are presented as Eqs. (24)-(28):

$$
\begin{aligned}
D & \equiv \frac{F}{V} \\
\mu & =D \\
G & \cong 0 \\
X & =Y_{X / G} G_{o}+Y_{X / M}\left(M_{o}-M\right) \\
M & =M_{o}-\frac{q_{M} X}{D} \\
P & =\frac{q_{P} X}{D}
\end{aligned}
$$

Therefore, knowing the dilution rate, $D$, the concentration of glycerol in the feed, $G_{o}$, the concentration of methanol in the feed, $M_{o}$, the residual concentration in the fermentor, $M$, the steady-state cell density, $X$, and the steady-state product concentration, $P$, it is possible to solve for $q_{M}, Y_{X / M}$, and $q_{P}$ as functions of $\mu$.

\section{RESULTS}

\section{Continuous Culture Experiments}

\section{Dynamic Behavior and Steady-State Conditions}

At least three reactor volumes of substrate solution $(15 \mathrm{~L})$ were allowed to flow through the system for each set of conditions. The system was judged to have arrived at steady state when differences in dissolved oxygen, cell density, and residual methanol concentration were considered small $(<10 \%)$ from one sample to the next. The dissolved oxygen trace was considered the most accurate measure of the system's state as it was logged continuously and had the least associated error with its measurement. An example of the dynamic behavior of the system over two step changes in feed methanol concentration and substrate feed rate is shown in Figure 1. As seen in the figure, all measured parameters show reasonably stable values in the highlighted ranges, and the associated cell density and product concentration data from these samples were considered valid. At least one steady state was achieved at dilution rates of 0.01 $\mathrm{h}^{-1}, 0.02 \mathrm{~h}^{-1}, 0.03 \mathrm{~h}^{-1}, 0.05 \mathrm{~h}^{-1}, 0.06 \mathrm{~h}^{-1}, 0.07 \mathrm{~h}^{-1}, 0.08 \mathrm{~h}^{-1}$, and $0.09 \mathrm{~h}^{-1}$, and one or more samples were taken from each and averaged to measure the cell density, the residual methanol and glycerol concentration, and the recombinant sea raven antifreeze protein concentration.

\section{Cell Growth on Mixed Glycerol/ Methanol Substrate}

A set of CSTR experiments was performed to determine the relationship between the dilution rate and the cell yield on methanol, the specific methanol consumption rate, and the specific product formation rate. One or more samples were taken for each set of conditions after the system was considered to have reached steady state based on stable and constant dissolved oxygen concentration values. The cell density was measured and the residual glycerol and methanol concentrations were determined by HPLC. These steady-state values, together with the substrate feed rate and feed glycerol and methanol concentrations, can be used to solve Eqs. (26) and (27) for the cell yield on methanol (with the stated assumption that the cell yield on glycerol is considered constant with a value of 0.4 based on batch growth data), and the specific methanol consumption rate as functions of the dilution rate. Figure 2 illustrates the cell yield on methanol $\left(Y_{X / M}\right)$ and the specific methanol consumption rate $\left(q_{M}\right)$ as functions of dilution rate $(D)$ at a constant residual methanol concentration of approximately $2 \mathrm{~g} / \mathrm{L}$.

As seen in Figure 2, there was an approximately linear increase in the cell yield on methanol as a function of the dilution rate from approximately 0.4 at $D=0.01 \mathrm{~h}^{-1}$ to 


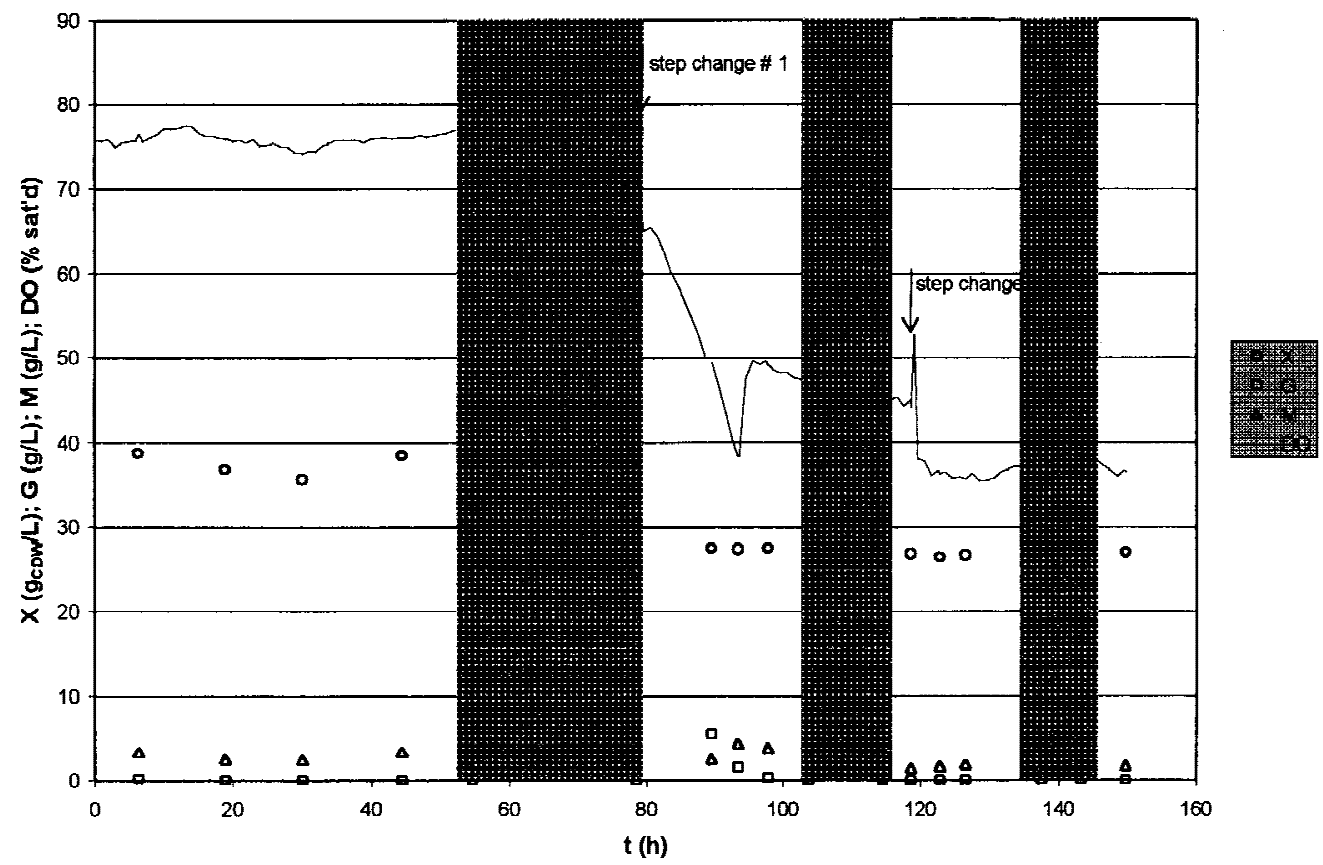

Figure 1. Dynamic behavior over two step changes in dilution rate and feed methanol concentration; $t=; 0$ to $79 \mathrm{~h}: D=; 0.01 \mathrm{~h}^{-1} ; M_{o}=; 48.8 \mathrm{~g} / \mathrm{L}$; $t=; 79$ to $119 \mathrm{~h}: D=; 0.07 \mathrm{~h}^{-1} ; M_{o}=; 7.2 \mathrm{~g} / \mathrm{L} ; t=; 119$ to $150 \mathrm{~h}: D=; 0.09 \mathrm{~h}^{-1} ; M_{o}=; 5.7 \mathrm{~g} / \mathrm{L}$. The data that were considered at steady state are highlighted in gray.

approximately 2 at $D=0.10 \mathrm{~h}^{-1}$. A cell yield of $>1$ above $D=0.06 \mathrm{~h}^{-1}$ occurred as a result of the assumption that the cell yield on glycerol was constant. That the cell yield varies with dilution rate and feed composition during mixed feeding of methylotrophic yeast, and that there is a synergistic effect of methanol and glycerol on cell growth in mixed feeding, is supported in the literature (Egli et al., 1986). The specific methanol consumption rate as a function of the dilution rate showed a single maximum at approximately $D=; 0.05 \mathrm{~h}^{-1}$ where the specific rate of methanol consumption was greatest. This behavior was consistent with the cell yield on methanol being a function of the dilution

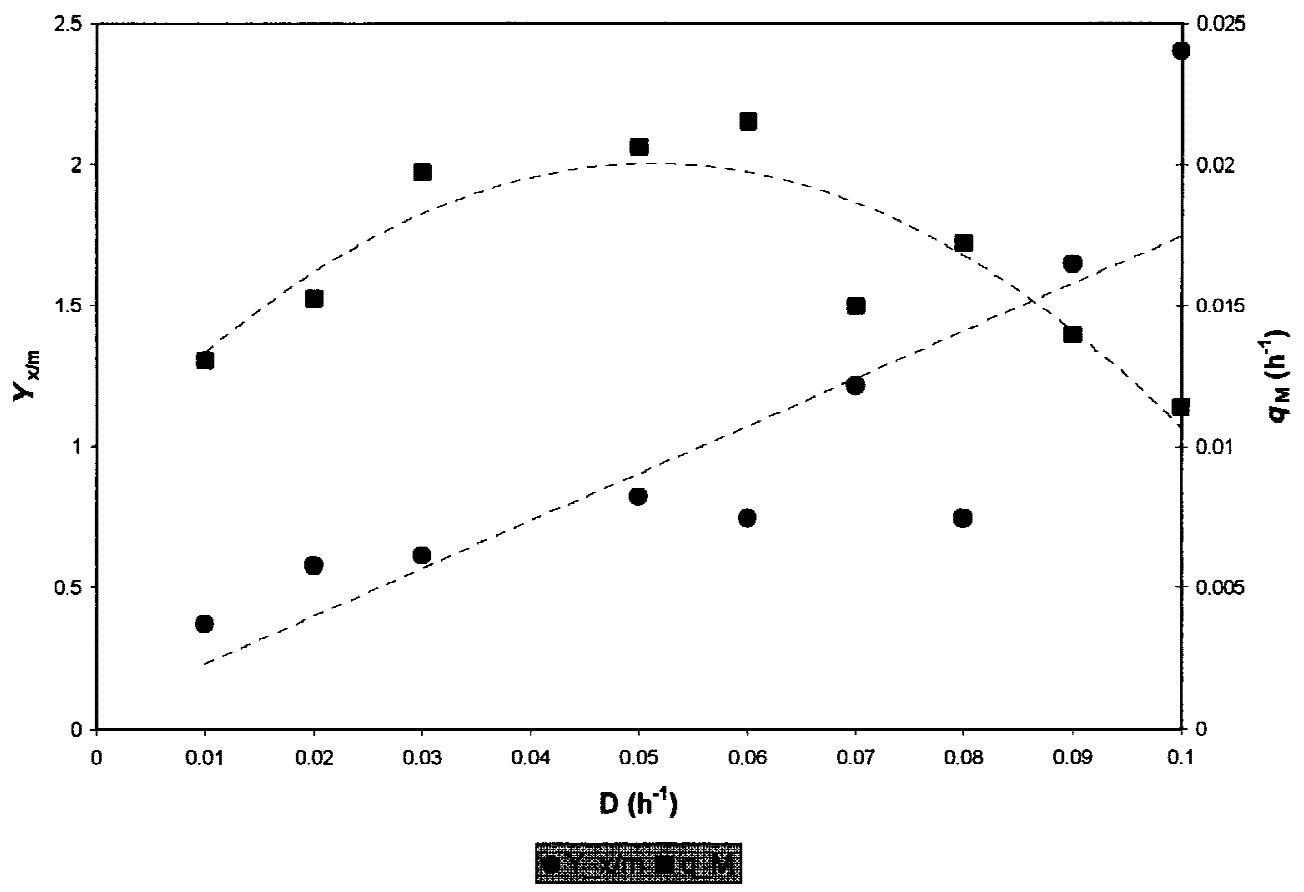

Figure 2. Cell yield on methanol $\left(Y_{X / M}\right.$, left axis) and specific methanol consumption rate $\left(q_{M}\right.$, right axis) as a function of the dilution rate $(D)$ in the continuous fermentation of $\mathrm{Mut}^{\mathrm{S}}$ recombinant $P$. pastoris using mixed methanol/glycerol feed. 
rate, because the specific rate of substrate consumption is related to the dilution rate by the inverse of the yield coefficient (i.e., $q_{M}=; 1 / Y_{X / M} \cdot D$ ).

\section{Recombinant Product Formation}

Through image analysis of properly exposed and calibrated western immunoblots, it was possible to determine steadystate recombinant sea raven AFP concentration in the continuous stirred-tank reactor (CSTR) fermentation samples. With this information, Eq. (28) can be solved to determine the specific heterologous protein production rate $\left(q_{P}\right)$ as a function of the dilution rate $(D)$. The steady-state srAFP concentration and the specific srAFP production rate are plotted as a function of $D$ in Figure 3.

The steady-state recombinant product concentration versus the dilution rate displays the $P \alpha 1 / D$ relationship to be expected based on Eq. (28). Also significant in Figure 3 is the increasing trend observed in $q_{P}$ with $D$. This trend was consistently upheld over the range studied, despite the high degree of scatter associated with the product concentration assay. This behavior was consistent with a type I fermentation where product formation is related to growth by a constant yield coefficient. The specific product formation rate showed no sign of repression by glycerol over the range studied. Significant repression by glycerol would have caused a decrease in the specific rate as the dilution rate increased. Although it was expected that glycerol repression would become more relevant as the dilution rate increased, at the maximum dilution rate studied of $0.10 \mathrm{~h}^{-1}$, there was no evidence of a maximum in the specific rate plot. The maximum productivity of the CSTR system over the range studied was approximately $1.6 \mathrm{mg} / \mathrm{L} \cdot \mathrm{h}$ at $D=0.10 \mathrm{~h}^{-1}$. This represented an increase of approximately $700 \%$ compared with the benchmark fed-batch run of Loewen et al. (1997).

\section{Fed-Batch Culture Experiments}

With results from the CSTR fermentation experiments, it was possible to estimate the required parameters $\left(q_{M}, Y_{X / M}\right.$, $\left.q_{P}\right)$ to use in the fed-batch model equations [Eqs. (1)-(5)] to predict time trajectories for the cell density, methanol concentration, and product concentration. As these parameters were defined strictly as functions of the dilution rate, it was necessary to keep the fed-batch system at a constant specific growth rate during the production phase. It was also necessary to carry out the fed-batch fermentation while keeping the residual methanol concentration at $\sim 2 \mathrm{~g} / \mathrm{L}$ during the production phase for the model to be considered valid using the derived parameter estimates. Therefore, the mixed-feed exponential feeding strategy [see Eqs. (15)-(17) in Model Development) was employed to design two fed-batch experiments at two different fixed specific growth rates. These runs was then undertaken experimentally to validate the accuracy of the model and to investigate the effect of a fixed growth rate during the fed-batch production phase on system productivity.

The fed-batch model required some initial conditions to be set by actual experimental data collected during the run to ensure a reasonable degree of accuracy. For example, the lag period at the start of the batch phase is difficult to

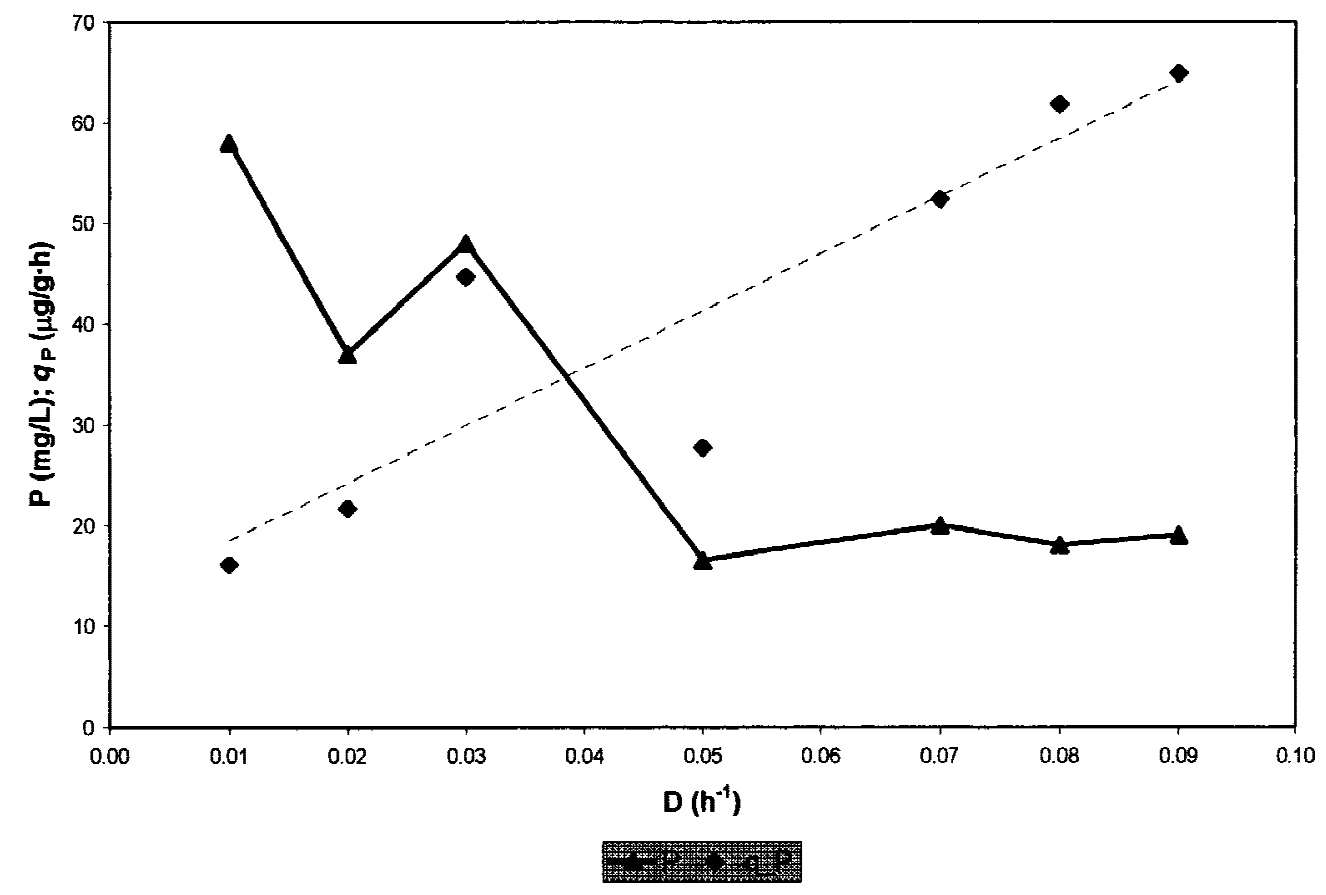

Figure 3. Steady-state recombinant srAFP product concentration $(P)$ and specific product formation rate $\left(q_{P}\right)$ as a function of the dilution rate $(D)$ in the continuous fermentation of $\mathrm{Mut}^{\mathrm{S}}$ recombinant $P$. pastoris using mixed methanol/glycerol feed. 
predict and must be used to adjust the model; the cell density and the system volume at the end of the induction phase (i.e., the start of the production phase) are required to implement the correct mixed-feed exponential feeding strategy both in terms of the flow rate profile and the feed methanol concentration required to maintain a residual methanol concentration between 1 and $2 \mathrm{~g} / \mathrm{L}$. The product concentration at the end of the induction phase is also required as an initial condition for the production phase model to be accurate. The parameters used in fed-batch fermentation experiments are presented in Table I. The fermentation runs were conducted according to the production-phase substrate feed-rate trajectories required by the exponential feeding strategy. The predicted and actual cell density, residual methanol concentration, and predicted and actual product concentration are plotted as functions of time in Figure 4A and B.

In both runs, the experimental cell density was very close to that predicted by the model. Therefore, the mixed substrate exponential feeding strategy assumption was feasible and it adequately supported cell growth, with average specific growth rates of $0.03 \mathrm{~h}^{-1}$ (Fig. 4A) and $0.07 \mathrm{~h}^{-1}$ (Fig. 4B) during the fed-batch production phase. Also, the predicted cell yield on methanol correctly estimated the resulting cell growth from the mixed feed. The methanol consumption rate was underestimated by the model, which resulted in the experimental residual methanol concentration being lower than the predicted value. However, the residual methanol concentration predicted by the model was very sensitive to small errors in the estimate of the specific methanol consumption rate. In Figure 4B describing the system at the higher growth rate, the residual methanol concentration prediction more closely matched the experimental data compared with the lower growth rate run. There was a jump in the residual methanol level at the very end of the fermentation as the cell growth reached its maximum, and growth began to slow due to a limitation of some other medium component, possibly nitrogen.

Significant discrepancies existed between the model and the srAFP concentration. The model underestimated by approximately $33 \%$ at the final timepoint, despite the correc- tion for the initial concentration at the start of the fed-batch production phase. In the product concentration profile, there was a clear inflection point at approximately $60 \mathrm{~h}$. This suggests that the specific formation rates changed at this point during the fed-batch production phase despite the fact that the growth rate remained constant. No cause for this change in specific rate was immediately apparent. The lower growth rate run (Fig. 4A) yielded a final product concentration of $175 \mathrm{mg} / \mathrm{L}$ in $81 \mathrm{~h}$, accounting for an overall productivity of $2.2 \mathrm{mg} / \mathrm{L} \cdot \mathrm{h}$. This represents a 6-fold increase in product yield and an 11-fold increase in productivity relative to a heuristic approach to srAFP (Loewen et al., 1997) fed-batch fermentation. In the higher growth rate run (Fig. 4B), the net product yield was $120 \mathrm{mg} / \mathrm{L}$ produced in $52 \mathrm{~h}$ of total fermentation time, and the overall productivity was $2.3 \mathrm{mg} / \mathrm{L} \cdot \mathrm{h}$, representing a substantial increase in both product yield and productivity compared with earlier results.

\section{DISCUSSION}

The key to accomplishing the goals of this study was to determine the relationship between cell growth and the production of the heterologous protein. More specifically, it was essential to define the specific rate of recombinant product formation, $q_{P}$, and the specific growth rate, $\mu$. This is because the specific growth rate is the major determinant of the cell growth time trajectory, and its relationship to the specific product formation rate, $q_{P}$, plays a crucial role in optimizing the fermentation (Modak et al., 1986).

\section{System Model}

Although cell growth was very closely modeled in this study, the model of recombinant protein expression must be considered as having been less successful. The parameter for the specific product formation rate derived from CSTR data does not accurately predict the product concentration during fed-batch operation despite the correction for the initial product concentration coming out of the induction

Table I. Parameters used in fed-batch model of recombinant $P$. pastoris fermentation.

\begin{tabular}{|c|c|c|c|}
\hline Parameter & Run A & Run B & Source \\
\hline Maximum specific growth rate, $\mu_{\max }\left(h^{-1}\right)$ & 0.26 & 0.27 & Batch data \\
\hline Cell yield on glycerol, $Y_{X / G}\left(\mathrm{~g}_{\mathrm{CDw}} / \mathrm{g}\right)$ & 0.40 & 0.44 & Batch data \\
\hline Lag period, $t_{\text {lag }}(\mathrm{h})$ & 1.5 & 1.5 & Batch data \\
\hline Feed glycerol concentration, $G_{o}(\mathrm{~g} / \mathrm{L})$ & 630 & 630 & Measured \\
\hline Feed methanol concentration, $M_{o}(\mathrm{~g} / \mathrm{L})$ & 255 & 65 & Measured \\
\hline Cell yield on methanol, $Y_{X / M}\left(\mathrm{~g}_{\mathrm{CDW}} / \mathrm{g}\right)$ & 0.61 & 1.73 & Figure 2 \\
\hline Volume at start of fed-batch phase, $V_{o}(\mathrm{~L})$ & 6.65 & 6.73 & Measured \\
\hline Cell density at start of fed-batch production phase, $X_{o}\left(\mathrm{~g}_{\mathrm{CDW}} / \mathrm{L}\right)$ & 20.1 & 21.3 & Batch data \\
\hline Specific growth rate during fed-batch production phase, $\mu\left(\mathrm{h}^{-1}\right)$ & 0.03 & 0.07 & Chosen \\
\hline Compound substrate feed concentration during fed-batch production phase, $S_{o}(\mathrm{~g} / \mathrm{L})$ & 885 & 695 & Calculated Eq. (13) \\
\hline Compound cell yield on substrate during fed-batch production phase, $Y_{x / S}\left(\mathrm{~g}_{\mathrm{CDw}} / \mathrm{g}\right)$ & 0.46 & 0.51 & Calculated Eq. (14) \\
\hline Specific methanol consumption rate during fed-batch production phase, $q_{M}\left(\mathrm{~g}_{M} / \mathrm{g}_{X} \cdot \mathrm{h}\right)$ & 0.020 & 0.015 & Figure 2 \\
\hline Specific srAFP production rate during fed-batch production phase, $q_{P}\left(\mu \mathrm{g}_{P} / \mathrm{g}_{X} \cdot \mathrm{h}\right)$ & 45 & 53 & Figure 3 \\
\hline srAFP concentration at start of fed-batch production phase, $P_{o},\left(\mathrm{mg}_{P} / \mathrm{L}\right)$ & 55 & 90 & Exp. data \\
\hline
\end{tabular}




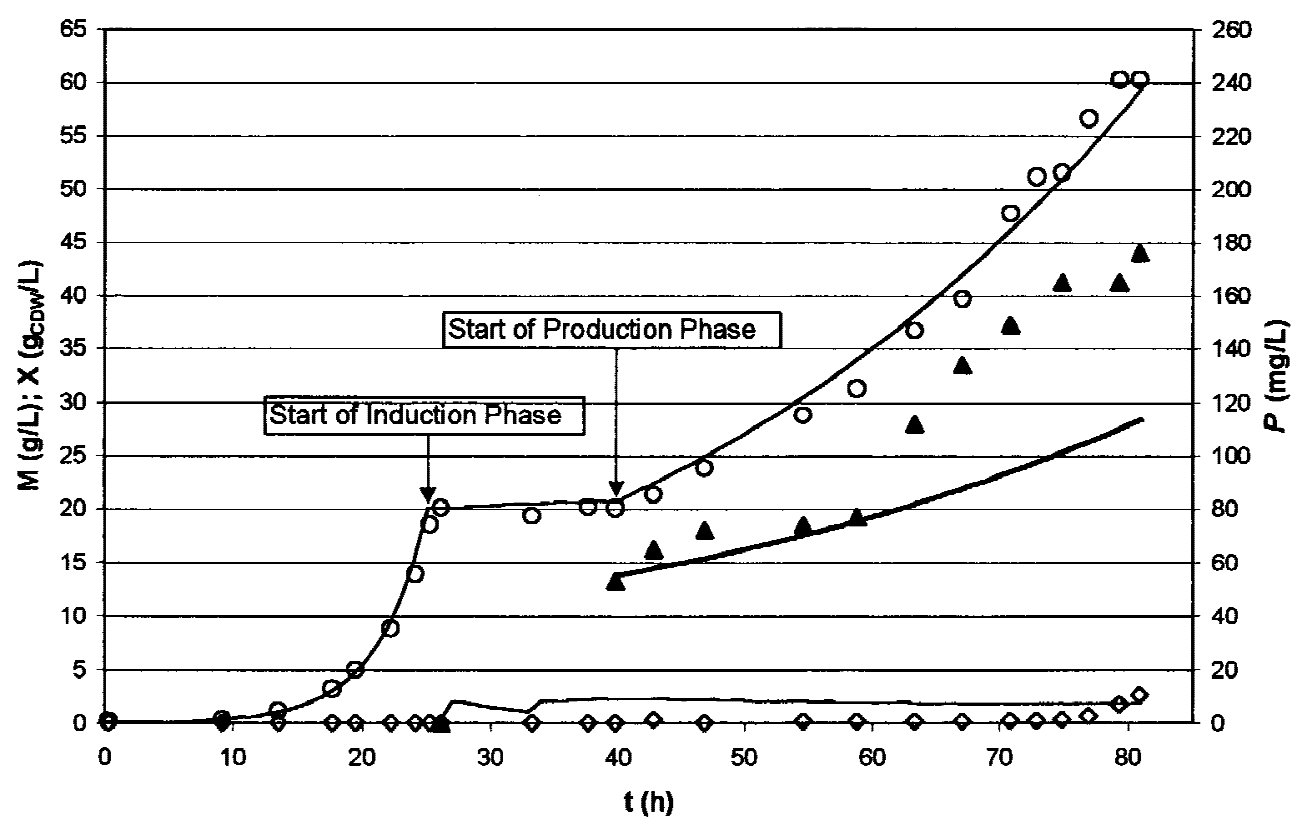

13.

a

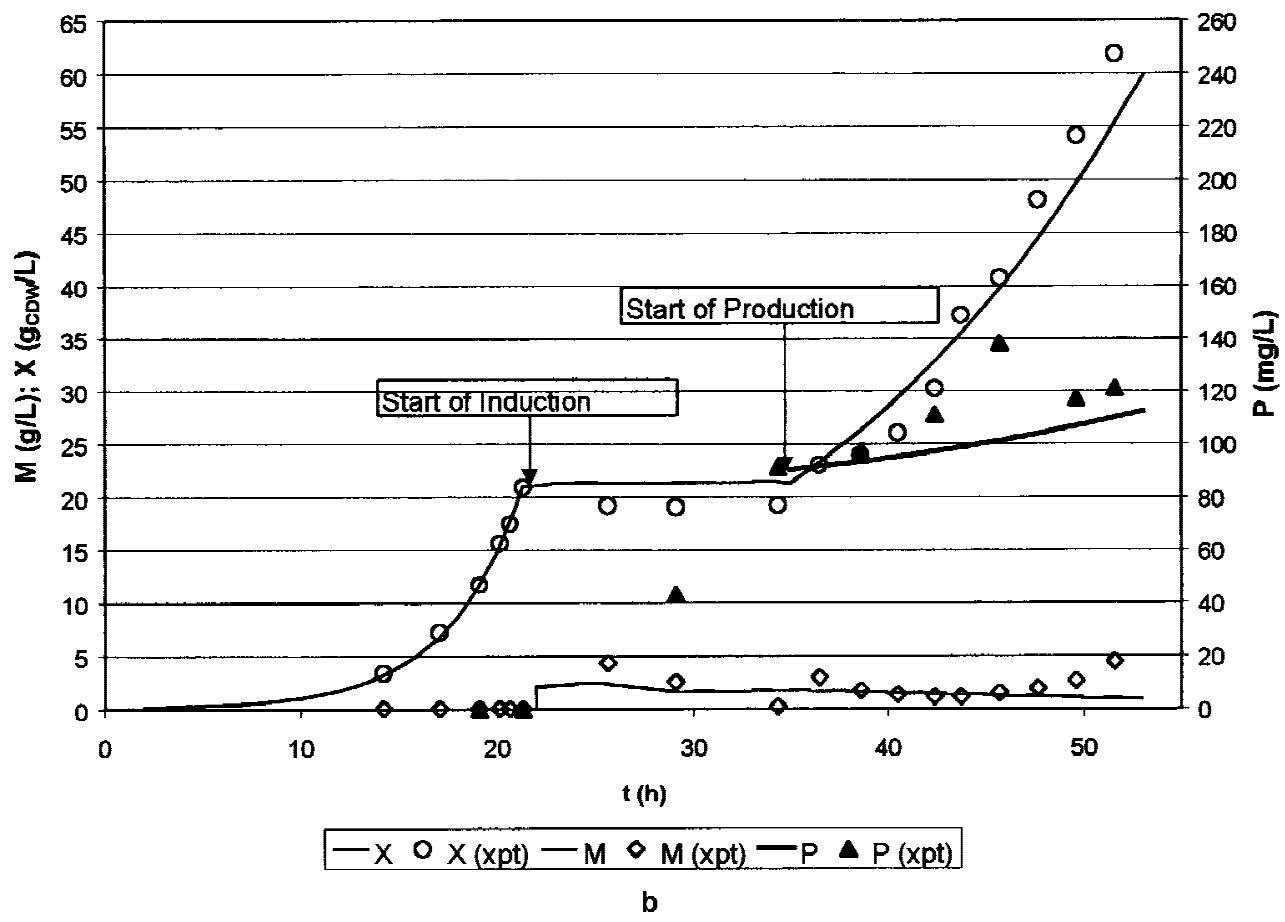

Figure 4. (a) Predicted and experimental (xpt) cell density $(X)$, residual methanol concentration $(M)$, and recombinant protein concentration $(P)$ in fed-batch fermentation of $\mathrm{Mut}^{\mathrm{s}}$ recombinant $P$. pastoris. Induction phase initiated by feeding methanol, and production phase initiated by feeding glycerol/methanol (run A). (b) Predicted and experimental (xpt) cell density $(X)$, residual methanol concentration $(M)$, and recombinant protein concentration $(P)$ in fed-batch fermentation of $\mathrm{Mut}^{\mathrm{s}}$ recombinant $P$. pastoris. Induction phase initiated by feeding methanol, and production phase initiated by feeding glycerol/methanol (run B).

phase. Using the specific product formation rate parameter derived from CSTR data, the fed-batch model underestimated the experimental product concentration in both the high- and low-growth-rate fed-batch runs. Perhaps even more significantly, there was a clear inflection point in the experimental product concentration for the low growth rate fed-batch run. This is the result of a distinct change in the specific rate of product formation. Based on all other process parameters recorded during this experiment (cell density, residual glycerol and methanol concentration, dissolved oxygen concentration, substrate feed rate, $\mathrm{pH}$, temperature), there was no significant change in process 
conditions at or near the time that this shift occurred. It is evident that further work is required to determine the factors affecting the heterologous protein expression rate. The mechanisms of heterologous protein expression and secretion in eukaryotes are complex, and the discrepancies between the model and the experimental data are examples of the incomplete understanding of these mechanisms.

\section{CSTR Versus Fed-Batch Operation}

The implementation of an effective mixed feeding strategy allowed continuous high-cell-density fermentation of a $\mathrm{Mut}^{\mathrm{S}}$ strain of Pichia pastoris with all of its associated benefits, including higher productivity and the ability to operate continuously at near-optimal conditions. Mixed feeding takes advantage of the higher cell densities and dilution rates possible with growth on glycerol while ensuring that glycerol is limiting to prevent repression of heterologous protein production and that methanol is present to induce its production.

The concentration of glycerol and methanol in the feed can be increased to further increase the cell density in the CSTR. Despite the scatter in the recombinant protein concentration data, the increasing trend in the specific rate of product formation and productivity based on product with dilution rate was consistent. Therefore, a CSTR system will yield a higher productivity compared with a fed-batch system, and the dilution rate should be set at the maximum of the productivity curve. In this study, the maximum dilution rate examined was $0.10 \mathrm{~h}^{-1}$ and both the specific product formation rate and the productivity were still increasing. Further work will be necessary to extend the range of dilution rate and to determine the true maximum.

However, according to the fed-batch data, there are a number of discrepancies between them and the CSTR data. The high specific rate of product formation seen in the induction phase of both runs was much higher than that observed in the CSTR experiments. CSTR data indicate that fed-batch productivity would be maximized by pursuing as high a growth rate as possible during the fed-batch production phase. The overall effect of the discrepancies between fed-batch and CSTR data was to make the net productivity of the fed-batch system greater than that of the CSTR system at the equivalent dilution rate. However, given the increasing trend in the productivity with dilution rate, and the possibility of a steady-state cell density up to twice the value used in the CSTR studies, a continuous system could be run at a productivity of approximately $3 \mathrm{mg} / \mathrm{L} \cdot \mathrm{h}, 50 \%$ greater than that seen in the fed-batch runs. This increase in productivity must be balanced against the greater probability of contamination in continuous fermentation and a lower recombinant protein concentration.

The question of optimal operating mode and operating conditions has to be settled on issues beyond the volumetric productivity. Product concentration and the concentration of other proteins in the fermentation broth play a key role in determining the downstream processing steps, and the entire process needs to be evaluated on an overall cost basis, where issues such as oxygen supplementation, cooling, and raw material costs need to be considered in the context of overall process economics.

This work represents only the first step toward enhancing production of recombinant proteins with this promising expression system. Despite some significant discrepancies between the model and experimental data, the approach of implementing a rational strategy have led to considerable gains in process productivity. These gains illustrate the promise of this model-based approach in the Pichia pastoris expression system.

The authors are very grateful to Dr. Peter Davies of the Queen's University Department of Biochemistry and Dr. Virginia Walker of the Queen's Department of Biology, and their lab groups, for their indispensable assistance in completing this study.

\section{References}

Baheri HR, Roesler WJ, Hill GA. 1997. Modeling of recombinant bacteria fermentation for enhanced productivity. Biotechnol Techn 11:47-50.

Cregg JM, Barringer KJ, Hessler AY, Madden KR. 1985. Pichia pastoris as a host system for transformations. Mol Cell Biol 5:3376-3385.

Cregg JM, Higgins DR. 1995. Production of foreign proteins in the yeast Pichia pastoris. Can J Bot 73(suppl 1):S891-S897.

Cregg JM, Vedvick TS, Raschke WC. 1993. Recent advances in the expression of foreign genes in Pichia pastoris. Bio/Technology 11: 905-910

d'Anjou MC, Daugulis AJ. 2000. Mixed-feed exponential feeding for fedbatch culture of recombinant methylotrophic yeast. Biotechnol Lett 22:341-346.

Egli T, Bosshard C, Hamer G. 1986. Simultaneous utilization of methanol-glucose mixtures by Hansenula polymorpha in chemostat: Influence of dilution rate and mixture composition on utilization pattern. Biotechnol Bioeng 28:1735-1741.

Faber KN, Harder W, Geert AB, Veenhuis M. 1995. Review: Methylotrophic yeasts as factories for the production of foreign proteins. Yeast 11:1331-1344.

Hardjito L, Greenfield PF, Lee PL. 1992. A model of $\beta$-galactosidase production with a recombinant yeast Saccharomyces cerevisiae in fedbatch culture. Biotechnol Progr 8:298-306.

Harlow E, Lane D. 1988. Antibodies: A laboratory manual. New York: Spring Harbor Laboratory Press, Cold Spring Harbor. 726 p.

Hollenberg CP, Gellissen G. 1997. Production of recombinant proteins by methylotrophic yeasts. Curr Opin Biotechnol 8:554-560.

Loewen MC. 1997. Mechanistic analyses of two structurally disparate antifreeze proteins: Types I and II. PhD thesis, Queen's University. $184 \mathrm{p}$.

Loewen MC, Liu X, Davies PL, Daugulis AJ. 1997. Biosynthetic production of type II antifreeze protein: Fermentation by Pichia pastoris. Appl Microbiol Biotechnol 48:480-486.

Modak JM, Lim HC, Tayeb YJ. 1986. General characteristics of optimal feed rate profiles for various fed-batch fermentation processes. Biotechnol Bioeng 28:1396-1407.

Romanos M. 1995. Advances in the use of Pichia pastoris for high-level gene expression. Curr Opin Biotechnol 6:527-533.

Romanos MA, Scorer CA, Clare JJ. 1992. Foreign gene expression in yeast: A review. Yeast 8:423-488.

Schagger H, von Jagon G. 1987. Tricine-sodium dodecyl sulfatepolyacrylamide gel electrophoresis for the separation of proteins in the range from 1-100 $\mathrm{kDa}$. Anal Biochem 166:368-379.

Sreekrishna K, Brankamp RG, Kropp KE, Blankenship DT, Tsay J-T, Smith PL, Wierschke JD, Subramaniam A, Birkenberger LA. 1997. Strategies for optimal synthesis and secretion of heterologous proteins in the methylotrophic yeast Pichia pastoris. Gene 190:55-62.

Vedvick TS. 1991. Gene expression in yeast: Pichia pastoris. Curr Opin Biotechnol 2:742-745. 